Original Article (short paper)

\title{
Moderate-intensity exercise training improves long-term memory in fructose-fed rats
}

\author{
Macário Arosti Rebelo ${ }^{1}$ (D) , Claudia Maria Padovan² (D), Adriana Colsera Pereira ${ }^{2}$ (D) , Camila de Moraes ${ }^{1}$ \\ ${ }^{1}$ Universidade de São Paulo, Escola de Educação Física e Esporte de Ribeirão Preto, Ribeirão Preto, SP, \\ Brasil; ' ${ }^{2}$ Universidade de São Paulo, Faculdade de Filosofia, Ciências e Letras de Ribeirão Preto, \\ Ribeirão Preto, SP, Brasil; ${ }^{3}$ Instituto de Neurociências e Comportamento (INeC), Ribeirão Preto, SP, Brasil.
}

Associate Editor: Fernanda B. M. Priviero. Augusta University, US.

\begin{abstract}
Aim: Animal disease model studies are widely used to show the effectiveness of physical exercise to improve cognitive function. Thus far, few studies are investigating the effects of exercise training on memory performance in fructose feed animals. Method: The present study investigated the effects of physical exercise protocol carried out with three weekly sessions, on the short and long-term memory performance of animals fed with fructose. Male Wistar rats were divided into sedentary (SD); sedentary+fructose (SDF); trained (TR); trained+fructose (TRF). Treadmill running sessions consisted of a five-minute warm-up at 20\% maximum speed (MS) followed by 40 minutes at $40 \% \mathrm{MS}$ and a 5-minute cool-down at 20\% MS. Sessions were carried out three days a week (Monday, Wednesday, and Friday) for six weeks. Object Recognition Test was used to evaluate short and long-term memory. Results: The access to fructose altered food intake and drinking volume, as fructose-fed animals had lower food intake (SDF: $-27 \%$ and TRF: $-24 \%$ ) and higher drinking volume (SDF: $+49 \%$ and TRF: $+45 \%$ ) than an animal which drank water. Trained groups had lower epididymal fat pad compared to their sedentary counterparts (TR: $-30 \%$ and TRF: $-11 \%$ ). In addition, TR and TRF had an improvement in glucose tolerance. Regarding memory performance, neither fructose intake nor exercise training influenced short-term memory. On the other hand, long-term memory was enhanced by exercise training. An improvement of about 39\% was observed for TR and the largest effect was seen for TRF, which improved long-term memory in $76 \%$. Conclusion: In conclusion, moderate-intensity exercise training, carried out three days a week, for six weeks was effective to improve long-term memory in fructose-fed rats. This result was related neither to the visceral fat amount nor to the glucose metabolism. Further studies should considerer the investigation regarding cerebral areas, associated with memory that might be adapted facing physical exercise.
\end{abstract}

Key words: physical exercise, fructose, cognitive function

\section{Introduction}

The increase in processed food intake, which has high fructose content, has been linked to a higher prevalence of cardiovascular diseases, non-alcoholic fatty liver disease, type 2 diabetes, and obesity $^{1,2}$. Excessive fructose consumption induces oxidative stress, insulin resistance, high blood pressure, and impaired appetite hormone signaling ${ }^{3}$, features that could be associated with changes in cognitive function, which comprises the phases of the information process, perception, learning, memory, attention, surveillance, reasoning and problem solving, psychomotor functioning, reaction time, movement time and performance speed ${ }^{4-6}$.

The mechanisms in which excessive fructose intake might lead to cognitive impairment are not yet fully elucidated ${ }^{7}$. The hypotheses include insulin resistance that would lead to the functional decline of hippocampus ${ }^{8,9}$, increased blood pressure, oxidative stress, and inflammation that impairs short and longterm working memory ${ }^{10}$.
On the other hand, the beneficial effects of exercise training to prevent or manage cardiovascular ${ }^{11}$ and metabolic diseases ${ }^{12}$ is well recognized. Animal model studies carried out in our laboratory have shown that moderate-intensity aerobic exercise, performed five days a week, preserved endothelial function in rats fed a highly palatable diet rich in sugar and fat ${ }^{13}$, prevented weight gain and the accumulation of visceral fat ${ }^{14}$.

Regarding the impact of exercise training on cognitive performance, the majority of studies have investigated the effects of aerobic exercise training to revert memory impairment. Aerobic exercise, performed five days a week, was effective to counteract neurodegeneration, improve spatial learning and long-term memory in a rat model of Alzheimer ${ }^{15}$. Improvement in short-term memory and spatial learning was seen in rats that suffered cortex injury and were submitted to daily exercise sessions ${ }^{16}$, a similar result was seen in an intracerebral hemorrhage model ${ }^{17}$. Type 1 diabetic rats have also performed better in spatial memory testing after physical training ${ }^{18}$. One of the few studies carried out with healthy animals showed that Wistar 
rats submitted to aerobic exercise training had working memory and spatial memory improved ${ }^{19}$.

Nevertheless, an emerging question in sports science is related to the establishment of a minimal amount of physical exercise, which might cause improvement in different physiological systems function. It is already known that physiological adaptations, including cerebrovascular, are dependent on physical exercise intensity ${ }^{20}$.

Animal disease model studies are widely used to show the effectiveness of physical exercise to counteract neurodegeneration and improve cognitive function. These studies were carried out using exercise training protocols with five weekly sessions that take up to 60 minutes per session. Taking into account the prevalence of insufficient physical activity in adults this training protocol might not be feasible, as most people do not accumulate this amount of exercise per week ${ }^{21}$. Considering the importance of translational research, the present study investigated the effects of physical exercise protocol carried out with three weekly sessions, on the short and long-term memory performance of animals fed with fructose.

\section{Methods}

\section{Animals and procedures}

Forty male Wistar rats ( $444 \pm 46 \mathrm{~g} ; 70$ days old) were divided into 4 groups according to the protocol of exercise training (sedentary or trained) and drink offered (water or fructose solution) as follows: sedentary ( $\mathrm{SD}, \mathrm{n}=9)$, sedentary + fructose (SDF, $n=9)$, training (TR, $n=11)$, training + fructose (TRF, $n=11)$. The animals were randomized into groups after a one-week treadmill familiarization. Only the rats, which were able to maintain a running behavior, were randomly allocated in trained groups.

Animals were housed in collective polypropylene cages $(41 \times 34 \times 30 \mathrm{~cm})($ five animals/cage) and kept under a $12 \mathrm{~h} \mathrm{light/}$ dark cycle. For the duration of the experiment ( 7 weeks), animals had free access to standard chow and drinking tap water or fructose solution (10\%). Food intake was measured daily by weighing the remaining chow and subtracting the chow amount placed the day before on the cage top. The values were divided by the number of rats maintained in the cage. Water/fructose intake was also measured subtracting the remaining amount of liquid from the amount placed into the drinker. Body weight was also measured once a week. After $48 \mathrm{~h}$ of the last exercise session, animals were submitted to overnight fasting followed by decapitation under anesthesia with Urethane $(25 \%, 1.25 \mathrm{~g} /$ $\mathrm{kg}$ ). Epidydimal fat was excised and weighted. During fasting, the fructose solution was replaced by tap water.

All procedures were reviewed and approved by the Ethics Committee on Animal Use in Research (CEUA/PUSP-RP protocol number 2016.1.462.90.7) in compliance with the "Principles of laboratory animal care" (NIH publication No 8623, revised 1985) and the national law (CONCEA publication $\left.\mathrm{N}^{\mathrm{o}} 11.794,2008\right)$.

\section{Incremental maximal treadmill test and exercise training protocol}

Before the incremental maximal test and training protocol, animals were submitted to a familiarization period with increments in running speed and minutes along the week (Table 1). After this period, rats underwent an incremental treadmill test (adapted from ${ }^{22}$ ), beginning at $11.6 \mathrm{~m} / \mathrm{min}$ followed by progressive increases of $1.6 \mathrm{~m} / \mathrm{min}$ every 2 minutes until $20 \mathrm{~m} /$ $\mathrm{min}$. Subsequently, the speed was increased by $3.2 \mathrm{~m} / \mathrm{min}$ until exhaustion (determined when the animal touched the bottom of the bay five times within one minute). The exhaustion speed was used to determined maximal speed (MS) using the following equation: $\mathrm{MS}=\mathrm{W} 1+(\mathrm{W} 2 \times \mathrm{t} / 120)$, where $\mathrm{W} 1=$ exhaustion speed, $\mathrm{W} 2=$ speed increase $(1.6 \mathrm{~m} / \mathrm{min}$ or $3.2 \mathrm{~m} / \mathrm{min}), \mathrm{t}=$ duration of the incomplete test stage ${ }^{23}$.

Table 1 - Scheme of running familiarization

\begin{tabular}{cccccc}
\hline Days of familiarization & 1st & 2nd & 3th & 4th & 5th \\
\hline Speed (m/ min) & 5 & 5 & 10 & 10 & IMT \\
Exercise time (minutes) & 30 & 60 & 30 & 60 & \\
\hline
\end{tabular}

IMT: Incremental Maximal Test

\section{Exercise training protocol}

Physical exercise sessions were carried out on Mondays, Wednesdays, and Fridays, in the same period of the day (11 a.m to 2 p.m.) for six weeks. Running sessions consisted of a five-minute warm-up at $20 \% \mathrm{MS}$ followed by running at $40 \%$ MS for 40 minutes and a cool-down at 20\% MS for 5 minutes. At the final of the $3^{\text {rd }}$ week, trained rats underwent Incremental Maximal Test, as previously described, to adjust speed training and guarantee the maintenance of exercise intensity during the six weeks.

\section{Short and Long-term memory evaluation}

Object Recognition Test was used to evaluate memory performance as previously described ${ }^{24}$. Briefly, on the first day, rats were submitted to a habituation session in an open field $(45 \times 40 \times 60 \mathrm{~cm})$, during which they were placed in the empty arena for $5 \mathrm{~min}$. On the following day, rats were given one 5-min training trial in which they were exposed to two identical objects (A1 and A2). The objects were positioned in two adjacent corners, $9 \mathrm{~cm}$ from the walls. Ninety minutes after the training trial, rats were allowed to explore the open field for 5 min in the presence of two objects: the familiar object $A$ and a novel object $B$, which are placed in the same locations as in the training trial. In this trial, short-term memory was evaluated. On the long-term memory testing trial $(24 \mathrm{~h}$ after the training trial), rats were allowed to explore the open field for $5 \mathrm{~min}$ in the presence of two objects: the familiar object $A$ and a third novel object C. All objects presented similar textures, colors, and sizes, but distinctive shapes. Object exploration was measured 
using two stopwatches to record the time spent exploring the objects during the experimental sessions. Sniffing or touching the object with the nose was considered as exploration behavior. The recognition index (RI) for each animal was determined using the following equation: $\mathrm{RI}=\mathrm{TB} /(\mathrm{TA}+\mathrm{TB})$, as TA: time spent exploring the knowing object; TB: time spent exploring the novel object.:

\section{Glucose Tolerance Test}

Being fasting for 8 hours, glycaemia was determined before and 30, 60, 90, and 120 minutes after intraperitoneal glucose injection $(2 \mathrm{~g} / \mathrm{kg})(25)$. Blood samples were collected from the animal tail to determine blood glucose using test strips (AccuCheckAdvantage- Roche). The area under the curve was calculated using GraphPad Prism software.

\section{Statistical procedures}

Data are presented as means \pm standard error of the mean (SEM). All data were assessed for normality using Kolmogorov and Smirnov test. Analysis of variance (two-way ANOVA) followed by Bonferroni post-hoc test was used to identify differences between groups. Factors analyzed were exercise (yes/no) and diet (fructose or water). The strength of association between independent variables (memory performance, glucose tolerance, and epididymal fat mass) was determined by the Pearson correlation coefficient. Data analysis was done using GraphPad Prism software. Statistical significance was considered at $5 \%(\mathrm{P}<0.05)$.

\section{Results}

Body weight gain was not altered either by fructose $\left(\mathrm{F}_{(1 ; 38)}=0.43, \mathrm{p}=0.51\right)$ or physical exercise $\left(\mathrm{F}_{(1 ; 38)}=2.08, \mathrm{p}=0.16\right)$. However, epididymal fat mass was affected by either fructose intake $\left(\mathrm{F}_{(1 ; 38)}=11.65, \mathrm{p}=0.002\right)$ or physical exercise $\left(\mathrm{F}_{(1 ; 38)}=5.32\right.$, $\mathrm{p}=0.03$ ) without interaction between factors. Trained groups had diminished fat mass compared with their sedentary counterparts (about 30\% for TR and 11\% for TRF). The results are in figures $1 \mathrm{~A}$ and $1 \mathrm{~B}$. Fructose influenced food intake and drinking volume, as fructose-fed animals had lower food intake $\left(\mathrm{F}_{(1 ; 38)}=33.35\right.$, $\mathrm{p}<0.001$, fig $1 \mathrm{C})$ and higher drinking volume $\left(\mathrm{F}_{(1 ; 38)}=24.01\right.$, $\mathrm{p}<0.001$, fig 1D) than an animal which drank water. Interaction between physical exercise and diet was observed for drinking volume $\left(\mathrm{F}_{(1 ; 38)}=7,07, \mathrm{p}=0.02\right)$, highlighting the different effects of physical exercise on drinking volume between trained groups. While SD and TR had also the same drinking volume in the $6^{\text {th }}$ week, TRF tends to drink less than SDF (fig 1D).

Physical exercise prevented the raise of fasting glucose $\left(\mathrm{F}_{(1 ; 38)}=4.83, \mathrm{p}=0.04\right.$, fig $\left.3 \mathrm{~A}\right)$ and provided a better glucose tolerance, as demonstrated by a lower area under the curve in TR and TRF $\left(\mathrm{F}_{(1 ; 38)}=8.15, \mathrm{p}=0.01\right.$, fig $2 \mathrm{~B}$ and $\left.2 \mathrm{C}\right)$.

Regarding memory performance, neither fructose intake $\left(\mathrm{F}_{(1 ; 38)}=0.22, \mathrm{p}=0.64\right)$ nor exercise training $\left(\mathrm{F}_{(1 ; 38)}=0.00, \mathrm{p}=0.99\right)$ influenced short-term memory. On the other hand, long-term memory is enhanced by exercise training. An improvement of about 39\% was observed for TR and the largest effect was seen for TRF, which improved long-term memory by $76 \%$ (figure 3 ).

A weak correlation was observed between long-term memory performance and glucose tolerance in trained animals $(r=0.39$, $\mathrm{p}=0.08)$. A similar result was verified between long-term memory performance and epididymal fat mass $(r=-0.11, p=0.63)$ (figure 4$)$.
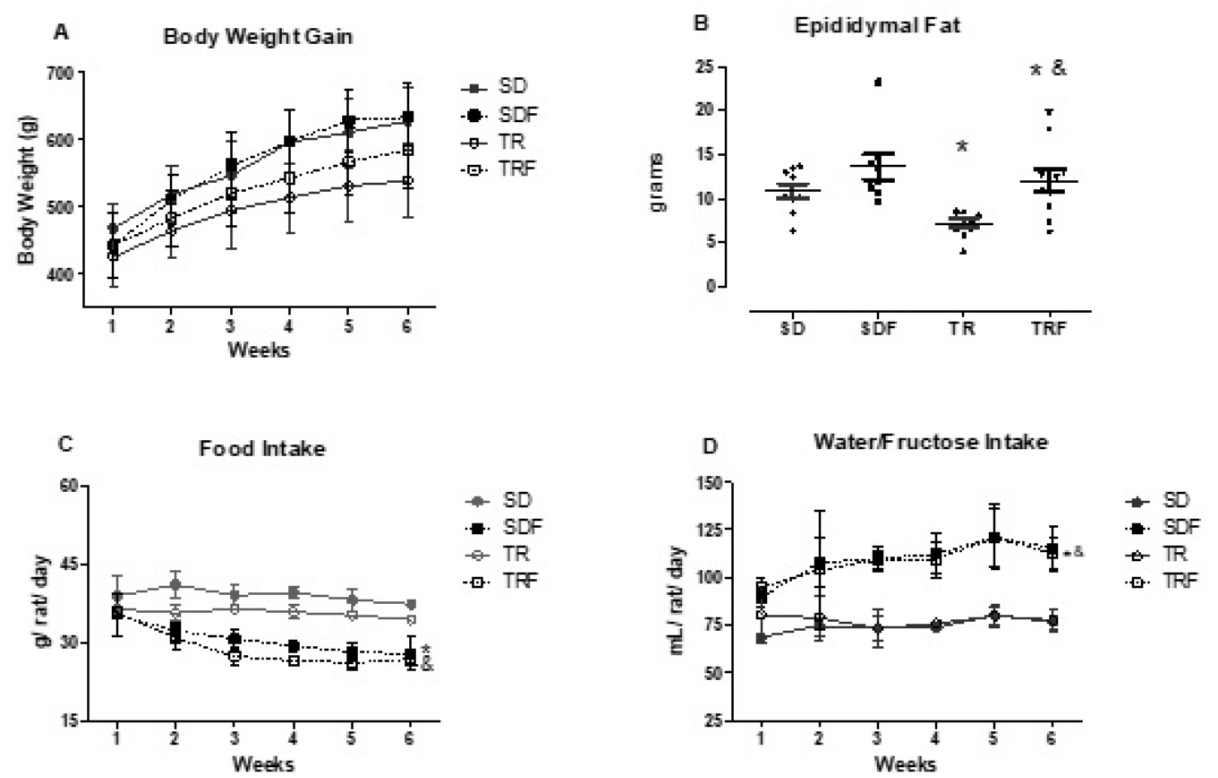

Figure 1 - Body weight gain (A), epididymal fat (B), food intake (C) and water or fructose intake (D) from Sedentary (SD), Trained (TR), Sedentary-Fructose $(\mathrm{SDF})$, Trained-Fructose $(\mathrm{TRF})$. Data are mean \pm SEM for $\mathrm{n}=9-11$ each group. Two-way ANOVA followed by Bonferroni post hoc ( $<<0.05)$. * physical exercise effect; \&fructose effect. 

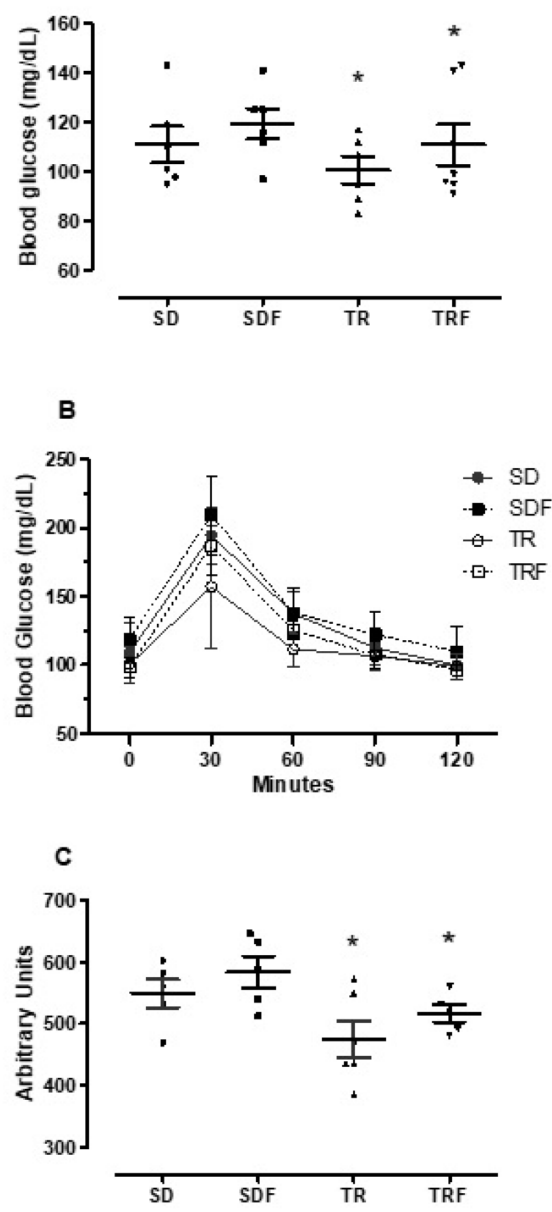

Figure 2 - Fasting Glucose (A), blood glucose kinetics during glucose tolerance test (B) and area under the curve from glucose tolerance test (C) from Sedentary (SD), Trained (TR), Sedentary-Fructose (SDF), Trained-Fructose (TRF). Data are mean \pm SEM for $n=6-7$ each group. Two-way ANOVA followed by Bonferroni post hoc $(\mathrm{p}<0.05)$. *physical exercise effect.
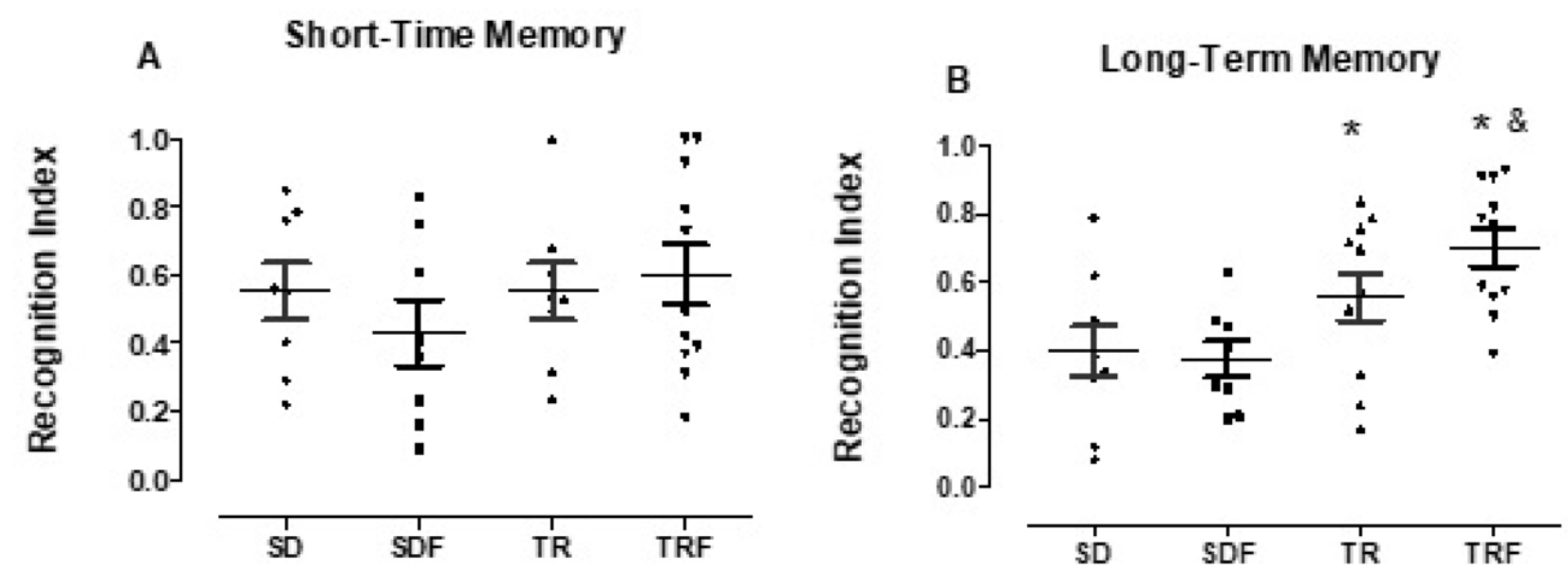

Figure 3 - Recognition Index for Object Recognition Test, carried out 90 minutes after previous object exposition (panel A) and Object Recognition Test carried out 24 hours after previous object exposition (panel B) from Sedentary (SD), Trained (TR), Sedentary-Fructose (SDF), Trained-Fructose (TRF). Data are mean \pm SEM for $\mathrm{n}=9$-11 each group. Two-way ANOVA followed by Bonferroni post hoc $(\mathrm{p}<0.05)$. *physical exercise effect; \&fructose effect. 
A

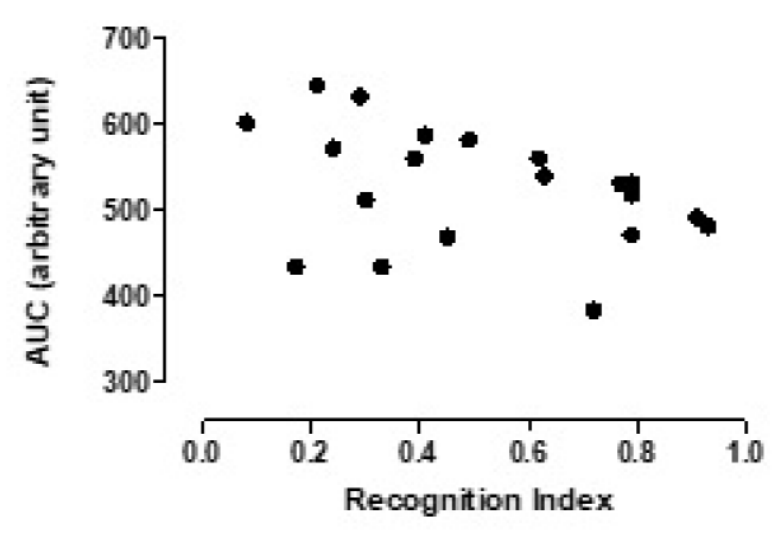

B

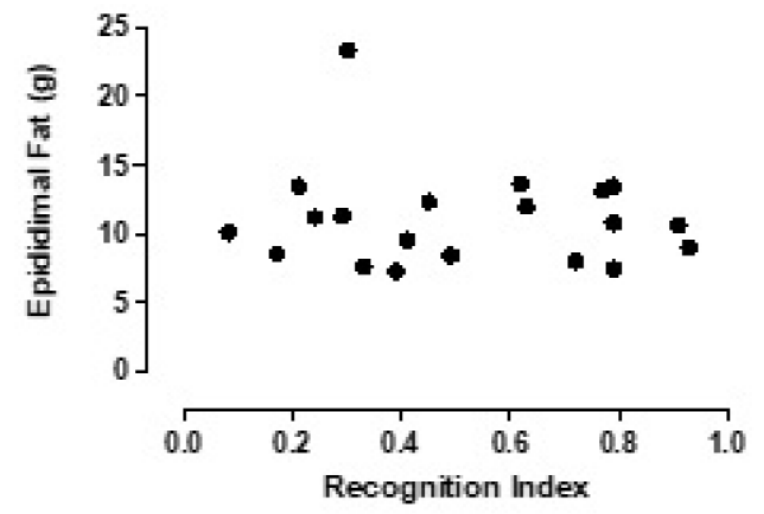

Figure 4 - Pearson correlation coefficient between the long-term memory performance and area under the curve from glucose tolerance test (panel A) and epididymal fat mass (panel B).

\section{Discussion}

Modern humans live in an environment that demands very low daily physical activity, as a result, chronic diseases prevalence raises as sedentary behavior is increase ${ }^{26}$. In addition, our environment is full of food cues that may promote overeating of high-sugar, high-fat palatable foods which in turn increases cardiometabolic disease ${ }^{27}$. The negative impact of physical inactivity and poor nutritional habit on cognitive performance are poorly studied ${ }^{5,28}$.

Our results have shown that fructose intake, per se, did not provoke major body weight or epidydimal fat gain. Similar results were seen in Fisher rats fed with a $60 \%$ fructose diet $^{29}$ and C57BL $/ 6$ mice fed with a $40 \%$ fructose diet $^{30}$. As expected, trained groups had lower epidydimal fat amounts compared to their sedentary counterparts. The effects of exercise training on the prevention of fat gain have already been demonstrated in rats fed with either standard chow or a high-fat diet ${ }^{14,31}$. Eating behavior was modified by fructose intake as SDF and TRF had lower food intake and higher drinking than SD and TR, which had water to drink. A similar result was observed in a previous study carried out with the same animal lineage and fructose solution concentration ${ }^{32}$. Exercise training carried out three days a week, did not affect eating behavior. However, other studies that submitted Wistar rats to five days a week treadmill training had demonstrated exercise effect to lower food intake $\mathrm{e}^{33,34}$.

Regarding fructose-fed effects on cognitive function, Sprague-Dawley rats fed with fructose $(10 \%)$ during eight months had impaired performance in spatial memory test ${ }^{9}$. A similar result was seen in C57BL/6J mice fed with fructose (15\%) during eight weeks ${ }^{35}$. However, this study failed to demonstrate the detrimental effect of fructose-fed on memory performance. It might be related to the lower fructose concentration offered $(10 \%)$ and/or the short-term duration of the experimental protocol (6 weeks).

On the other hand, the exercise training protocol proposed in the present study, which was carried out during six weeks with three days per week sessions was sufficient to enhance working memory performance in both trained groups. Improvement in spatial memory was seen in rats fed with a high-fat diet and submitted to treadmill running five days per week during eight weeks ${ }^{36}$. Mice fed with high fat or high fructose diets and submitted to treadmill running five days per week, during 23 weeks, did not have impairment on spatial memory and working memory ${ }^{37}$.

Our results demonstrated that trained animals had improvement in memory performance as well as better glucose metabolism and lower epididymal fat. Therefore, we investigate if peripheral factors influenced memory performance. It is well known that impaired peripheral glucose uptake and metabolism, due to insulin resistance, extends to impairment of insulin signaling within the hippocampus and impairs learning and memory ${ }^{38}$. A recent study demonstrates that insulin resistance, induced by LPS intracerebral injection, promotes memory impairment, which is nullified by intracerebral injection of in$\operatorname{sulin}^{39}$. In addition, obesity appears to have a deleterious effect on cognition as low-grade systemic inflammation precipitates local inflammation within the hypothalamus that alters synaptic plasticity, contributes to neurodegeneration, and even initiates brain atrophy ${ }^{40}$.

However, a non-significant association between the area under the curve (from GTT) and the long-term memory recognition index was observed. A similar result was detected between 
epididymal fat, which is the indirect measure of visceral fat, and memory performance. Thus, in the present study, neither systemic glucose metabolism nor fat amount was factors that affect memory performance.

Probably, local mechanisms would have a greater association with this response. The impairment of cognitive function has been attributed to cerebral microvascular complications ${ }^{41}$ as it was observed an inverse association between cerebral blood flow and cognitive performance in Alzheimer's patients ${ }^{42}$ and hypertensive middle-aged adults ${ }^{43}$. Endothelial dysfunction in brain capillaries would lead either to an increase in tau protein phosphorylation or its aggregation ${ }^{44}$. In addition, the increase of blood-brain barrier permeability, observed in high-fat diet mice, is related to inflammation and leucocyte recruitment precedes neurodegeneration and the memory performance decline ${ }^{45}$.

Physical exercise has long been recognized as a non-pharmacological approach that improves vascular function ${ }^{31,34}$, insulin signaling, and glucose metabolism ${ }^{14,46}$. The anti-inflammatory effect of physical exercise has also been described ${ }^{47}$. Recently, the existence of muscle-brain crosstalk was proposed. Myokines such as cathepsin B and irisin have been recognized as promoters of brain neurotrophic factor (BDNF) ${ }^{48}$. Physical exercise induces astrocytic plasticity and enhances cognitive performance in either healthy or diabetic rats ${ }^{18}$. The type and intensity of exercise training are a factor that might modulate brain adaptation response. In older rats, both moderate-intensity aerobic training and strength training improved spatial memory through distinct molecular mechanisms of neuroplasticity, showing that the effects of physical exercise on brain plasticity and spatial memory occur in an exercise type-dependent manner ${ }^{49}$. A recent study shows that Wistar rats, with cognitive impairment induced by scopolamine, submitted to treadmill running at moderate intensity $(70 \%$ of maximal speed) exhibit better memory performance and higher expression of BDNF and synaptophysin in the hippocampus than rats trained at a lower intensity ( $40 \%$ of maximal speed) (CEFIS et al., 2019). However, this dose-response effect appears to be limited. Female mice submitted to treadmill running at high intensity had no improvement in spatial discrimination and had a lower response in terms of the increase in neurotrophic factors compared with mice that ran at moderate intensity ${ }^{50}$.

In conclusion, moderate-intensity exercise training carried out three days a week, for six weeks was effective to improve long-term memory in fructose-fed rats. This result was neither related to the visceral fat amount nor glucose metabolism. Further studies should considerer the investigation regarding cerebral areas, associated with memory that might be adapted facing physical exercise.

\section{References}

1. Lakka TA, Laaksonen DE, Lakka HM, Männikkö N, Niskanen LK, Rauramaa R, et al. Sedentary lifestyle, poor cardiorespiratory fitness, and the metabolic syndrome. Med Sci Sports Exerc. 2003;35(8):1279-86.

2. Sacks FM, Lichtenstein AH, Wu JHY, Appel LJ, Creager MA, Kris-Etherton PM, et al. Dietary fats and cardiovascular disease:
A presidential advisory from the American Heart Association. Circulation. 2017;136(3):e1-23.

3. Page KA, Chan O, Arora J, Belfort-DeAguiar R, Dzuira J, Roehmholdt B, et al. Effects of fructose vs glucose on regional cerebral blood flow in brain regions involved with appetite and reward pathways. JAMA - J Am Med Assoc. 2013;309(1):63-70.

4. Antunes HK, De Mello MT, Santos-Galduróz RF, Galduróz JCF, Aquino Lemos V, Tufik S, et al. Effects of a physical fitness program on memory and blood viscosity in sedentary elderly men. Brazilian J Med Biol Res. 2015;48(9):805-12.

5. Holtkamp K, Konrad K, Müller B, Heussen N, Herpertz S, Herpertz-Dahlmann B, et al. Overweight and obesity in children with Attention-Deficit/Hyperactivity Disorder. Int J Obes. 2004;28(5):685-9.

6. Martin AA, Davidson TL. Human cognitive function and the obesogenic environment. Physiol Behav [Internet]. 2014;136:185-93. Available from: http://dx.doi.org/10.1016/j.physbeh.2014.02.062

7. Chou L, Lin C, Chen Y, Liao H, Lin S. A diet containing grape powder ameliorates the cognitive decline in aged rats with a long-term high-fructose-high-fat dietary pattern. 2016;34:52-60.

8. Stranahan AM, Norman ED, Lee K, Cutler RG, Telljohann RS, Egan JM, et al. Diet-induced insulin resistance impairs hippocampal synaptic plasticity and cognition in middle-aged rats. Hippocampus. 2008;18(11):1085-8.

9. Wu H-W, Ren L-F, Zhou X, Han D-W. A high-fructose diet induces hippocampal insulin resistance and exacerbates memory deficits in male Sprague-Dawley rats. Nutr Neurosci [Internet]. 2015;18(7):323-8. Available from: http://www.tandfonline.com/ doi/full/10.1179/1476830514Y.0000000133

10. Olver TD, Klakotskaia D, Ferguson BS, Hiemstra JA, Schachtman TR, Laughlin MH, et al. Carotid Artery Vascular Mechanics Serve as Biomarkers of Cognitive Dysfunction in AorticBanded Miniature Swine That Can Be Treated With an Exercise Intervention. J Am Heart Assoc. 2016;5(5):1-12.

11. Romero SA, Minson CT, Halliwill XR. The cardiovascular system after exercise. J Appl Physiol. 2017;122(4):925-32.

12. Keating SE, George J, Johnson NA. The benefits of exercise for patients with non-alcoholic fatty liver disease. Expert Rev Gastroenterol Hepatol. 2015;9(10):1247-50.

13. Oharomari LK, Garcia NF, De Freitas EC, Jordão Júnior AA, Ovídio PP, Maia AR, et al. Exercise training and taurine supplementation reduce oxidative stress and prevent endothelium dysfunction in rats fed a highly palatable diet. Life Sci [Internet]. 2015;139(86):91-6. Available from: http://dx.doi.org/10.1016/j.lfs.2015.08.015

14. Garcia NF, Da Silva CPV, Ferreira M, Oharomari LK, Rocha T, De Moraes C. 7-week aerobic exercise training reduces adipocyte area and improves insulin sensitivity in Wistar rats fed a highly palatable diet. Motriz Rev Educ Fis. 2016;22(1):12-7.

15. Bernardo TC, Beleza J, Rizo-Roca D, Santos-Alves E, Leal C, Martins MJ, et al. Physical exercise mitigates behavioral impairments in a rat model of sporadic Alzheimer's disease. Behav Brain Res [Internet]. 2020;379(July 2019):112358. Available from: https://doi.org/10.1016/j.bbr.2019.112358

16. Ko IG, Kim CJ, Kim H. Treadmill exercise improves memory by up-regulating dopamine and down-regulating D2 dopamine receptor in traumatic brain injury rats. J Exerc Rehabil. 2019;15(4):504-11. 
17. Zheng S, Zhang F, Liu Q, Jian R, Yang M. Exercise training increases spatial memory via reducing contralateral hippocampal NMDAR subunits expression in intracerebral hemorrhage rats. Neuropsychiatr Dis Treat. 2019;15:1921-8.

18. de Senna PN, Bagatini PB, Galland F, Bobermin L, do Nascimento PS, Nardin P, et al. Physical exercise reverses spatial memory deficit and induces hippocampal astrocyte plasticity in diabetic rats. Brain Res [Internet]. 2017;1655(July 2016):242-51. Available from: http://dx.doi.org/10.1016/j.brainres.2016.10.024

19. Wang XQ, Wang GW. Effects of treadmill exercise intensity on spatial working memory and long-term memory in rats. Life Sci [Internet]. 2016;149:96-103. Available from: http://dx.doi. org/10.1016/j.lfs.2016.02.070

20. Olver TD, Laughlin MH, Padilla J. Exercise and Vascular Insulin Sensitivity in the Skeletal Muscle and Brain. Exerc Sport Sci Rev. 2019;47(2):66-74.

21. Guthold R, Stevens GA, Riley LM, Bull FC. Worldwide trends in insufficient physical activity from 2001 to 2016 : a pooled analysis of 358 population-based surveys with 1.9 million participants. Lancet Glob Heal [Internet]. 2018;6(10):e1077-86. Available from: http://dx.doi.org/10.1016/S2214-109X(18)30357-7

22. Hohl R, Ferraresso RLP, De Oliveira RB, Lucco R, Brenzikofer R, De Macedo DV. Development and characterization of an overtraining animal model. Med Sci Sports Exerc. 2009;41(5):1155-63.

23. Kuipers H, Verstappen FTJ, Keizer HA, Geurten P, van Kranenburg G. Variability of aerobic performance in the laboratory and its physiologic correlates. Int J Sports Med. 1985;6(4):197-201.

24. de Lima MNM, Presti-Torres J, Caldana F, Grazziotin MM, Scalco FS, Guimarães MR, et al. Desferoxamine reverses neonatal iron-induced recognition memory impairment in rats. Eur J Pharmacol. 2007;570(1-3):111-4.

25. Bonora E, Targher G, Alberiche M, Bonadonna Rc, Saggiani F, Zenere Mb, et al. Closely Mirrors the Glucose Clamp. Diabets Care. 2000;23(1):57.

26. Archer E, Blair SN. Physical Activity and the Prevention of Cardiovascular Disease: From Evolution to Epidemiology. Prog Cardiovasc Dis [Internet]. 2011;53(6):387-96. Available from: http://dx.doi.org/10.1016/j.pcad.2011.02.006

27. Stanhope KL, Goran MI, Bosy-Westphal A, King JC, Schmidt LA, Schwarz JM, et al. Pathways and mechanisms linking dietary components to cardiometabolic disease: thinking beyond calories. Obes Rev. 2018;19(9):1205-35.

28. Clare L, Wu YT, Teale JC, MacLeod C, Matthews F, Brayne C, et al. Potentially modifiable lifestyle factors, cognitive reserve, and cognitive function in later life: A cross-sectional study. PLoS Med. 2017;14(3):1-14.

29. De Castro UGM, Dos Santos RAS, Silva ME, De Lima WG, Campagnole-Santos MJ, Alzamora AC. Age-dependent effect of high-fructose and high-fat diets on lipid metabolism and lipid accumulation in liver and kidney of rats. Lipids Health Dis. 2013;12(1):1-11.

30. de Oliveira Sá G, dos Santos Neves V, de Oliveira Fraga SR, Souza-Mello V, Barbosa-da-Silva S. High-intensity interval training has beneficial effects on cardiac remodeling through local renin-angiotensin system modulation in mice fed high-fat or high-fructose diets. Life Sci [Internet]. 2017;189(August):8-17. Available from: http://dx.doi.org/10.1016/j.lfs.2017.09.012
31. Sponton ACS, Silva FH, Araujo HN, Valgas Da Silva CP, De Moraes C, Antunes E, et al. Circulating Concentrations of Adipocytokines and Their Receptors in the Isolated Corpus Cavernosum and Femoral Artery from Trained Rats on a High-Fat Diet. J Vasc Res. 2017;54(1).

32. Sulis PM, Motta K, Barbosa AM, Besen MH, Da Silva JS, Nunes EA, et al. Impact of Fish Oil Supplementation and Interruption of Fructose Ingestion on Glucose and Lipid Homeostasis of Rats Drinking Different Concentrations of Fructose. Biomed Res Int. 2017;2017.

33. Dupas J, Feray A, Guernec A, Pengam M, Inizan M, Guerrero F, et al. Effect of personalized moderate exercise training on Wistar rats fed with a fructose enriched water 11 Medical and Health Sciences 1103 Clinical Sciences. Nutr Metab. 2018;15(1):1-12.

34. De Moraes C, Davel APC, Rossoni LV, Antunes E, Zanesco A. Exercise training improves relaxation response and SOD-1 expression in aortic and mesenteric rings from high caloric diet-fed rats. BMC Physiol. 2008;8(1).

35. Cisternas P, Salazar P, Serrano FG, Montecinos-Oliva C, Arredondo SB, Varela-Nallar L, et al. Fructose consumption reduces hippocampal synaptic plasticity underlying cognitive performance. Biochim Biophys Acta - Mol Basis Dis [Internet]. 2015;1852(11):2379-90. Available from: http://dx.doi. org/10.1016/j.bbadis.2015.08.016

36. Woo J, Shin KO, Park SY, Jang KS, Kang S. Effects of exercise and diet change on cognition function and synaptic plasticity in high-fat diet-induced obese rats. Lipids Health Dis [Internet]. 2013;12(1):1. Available from: Lipids in Health and Disease

37. Han TK, Leem YH, Kim HS. Treadmill exercise restores high fat diet-induced disturbance of hippocampal neurogenesis through $\beta 2$-adrenergic receptor-dependent induction of thioredoxin-1 and brain-derived neurotrophic factor. Brain Res [Internet]. 2019;1707(November 2018):154-63. Available from: https://doi. org/10.1016/j.brainres.2018.11.035

38. McNay EC, Ong CT, McCrimmon RJ, Cresswell J, Bogan JS, Sherwin RS. Hippocampal memory processes are modulated by insulin and high-fat-induced insulin resistance. Neurobiol Learn Mem [Internet]. 2010;93(4):546-53. Available from: http://dx.doi. org/10.1016/j.nlm.2010.02.002

39. Iloun P, Abbasnejad Z, Janahmadi M, Ahmadiani A, Ghasemi R. Investigating the role of P38, JNK, and ERK in LPS induced hippocampal insulin resistance and spatial memory impairment: Effects of insulin treatment. EXCLI J. 2018;17:825-39.

40. Miller AA, Spencer SJ. Obesity and neuroinflammation: A pathway to cognitive impairment. Brain Behav Immun [Internet]. 2014;42:10-21. Available from: http://dx.doi.org/10.1016/j. bbi.2014.04.001

41. De Silva TM, Faraci FM. Microvascular Dysfunction and Cognitive Impairment. Cell Mol Neurobiol. 2016;36(2):241-58.

42. Leeuwis AE, Benedictus MR, Kuijer JPA, Binnewijzend MAA, Hooghiemstra AM, Verfaillie SCJ, et al. Lower cerebral blood flow is associated with impairment in multiple cognitive domains in Alzheimer's disease. Alzheimer's Dement. 2017;13(5):531-40.

43. Gottesman RF, Schneider ALC, Albert M, Alonso A, BandeenRoche K, Coker L, et al. Midlife hypertension and 20-year cognitive change: The atherosclerosis risk in communities neurocognitive study. JAMA Neurol. 2014;71(10):1218-27. 
44. Faraco G, Hochrainer K, Segarra SG, Schaeffer S, Santisteban MM, Menon A, et al. Dietary salt promotes cognitive impairment through tau phosphorylation. Nature [Internet]. 2019;574(7780):686-90. Available from: http://dx.doi.org/10.1038/s41586-019-1688-z

45. Takechi R, Lam V, Brook E, Giles C, Fimognari N, Mooranian A, et al. Blood-brain barrier dysfunction precedes cognitive decline and neurodegeneration in a diabetic insulin-resistant mouse model: An implication for a causal link. Front Aging Neurosci. 2017;9(DEC):1-12.

46. Pauli JR, Ropelle ER. Effects of Physical Exercise in the Ampk $\alpha$ Expression and Activity in High-fat Diet-Induced Obese Rats. 2009;15(3):98-103.

47. Petersen AMW, Pedersen BK. The anti-inflammatory effect of exercise. J Appl Physiol. 2005;98(4):1154-62.

48. Pedersen BK. Physical activity and muscle-brain crosstalk. Nat Rev Endocrinol [Internet]. 2019;15(7):383-92. Available from: http://dx.doi.org/10.1038/s41574-019-0174-x

49. Vilela TC, Muller AP, Damiani AP, Macan TP, da Silva S, Canteiro $\mathrm{PB}$, et al. Strength and Aerobic Exercises Improve Spatial Memory in Aging Rats Through Stimulating Distinct Neuroplasticity Mechanisms. Mol Neurobiol [Internet]. 2017;54(10):7928-37. Available from: http://dx.doi.org/10.1007/s12035-016-0272-x

50. So JH, Huang C, Ge M, Cai G, Zhang L, Lu Y, et al. Intense exercise promotes adult hippocampal neurogenesis but not spatial discrimination. Front Cell Neurosci. 2017;11(January):1-12.

\section{Acknowledgment}

This research has financial support: grant \#2017/27042-6, São Paulo Research Foundation (FAPESP).

\section{Corresponding author}

Camila de Moraes

Universidade de São Paulo, Escola de Educação Física e Esporte de Ribeirão Preto, Av. Bandeirantes, 3900 - Vila Monte Alegre, 14030-680, Ribeirão Preto/SP. Telephone: +55 (16) 3315-0529.

Email: camimoraes@usp.br

Manuscript received on May 7, 2020

Manuscript accepted on September 7, 2020

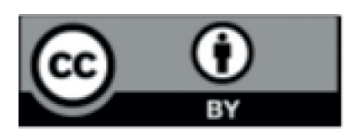

Motriz. The Journal of Physical Education. UNESP. Rio Claro, SP, Brazil - eISSN: 1980-6574 - under a license Creative Commons - Version 4.0 